\title{
Changing performance pressure between training and competition influences action planning because of a reduction in the efficiency of action execution
}

\author{
Cassell, V.E.; Beattie, Stuart; Lawrence, Gavin
}

\section{Anxiety, Stress and Coping}

DOI:

10.1080/10615806.2017.1373389

Published: 01/01/2018

Peer reviewed version

Cyswllt i'r cyhoeddiad / Link to publication

Dyfyniad o'r fersiwn a gyhoeddwyd / Citation for published version (APA):

Cassell, V. E., Beattie, S., \& Lawrence, G. (2018). Changing performance pressure between training and competition influences action planning because of a reduction in the efficiency of action execution. Anxiety, Stress and Coping, 31(1), 107-120.

https://doi.org/10.1080/10615806.2017.1373389

\footnotetext{
Hawliau Cyffredinol / General rights

Copyright and moral rights for the publications made accessible in the public portal are retained by the authors and/or other copyright owners and it is a condition of accessing publications that users recognise and abide by the legal requirements associated with these rights.

- Users may download and print one copy of any publication from the public portal for the purpose of private study or research.

- You may not further distribute the material or use it for any profit-making activity or commercial gain

- You may freely distribute the URL identifying the publication in the public portal ?
}

Take down policy

If you believe that this document breaches copyright please contact us providing details, and we will remove access to the work immediately and investigate your claim. 


\title{
Changing performance pressure between training and competition influences action planning because of a reduction in the efficiency of action execution
}

\author{
Cassell, V.E.; Beattie, Stuart; Lawrence, Gavin
}

\section{Anxiety, Stress and Coping}

DOI:

10.1080/10615806.2017.1373389

E-pub ahead of print: 25/09/2017

Peer reviewed version

Cyswllt i'r cyhoeddiad / Link to publication

Dyfyniad o'r fersiwn a gyhoeddwyd / Citation for published version (APA):

Cassell, V. E., Beattie, S., \& Lawrence, G. (2017). Changing performance pressure between training and competition influences action planning because of a reduction in the efficiency of action execution. Anxiety, Stress and Coping. DOI: 10.1080/10615806.2017.1373389

\footnotetext{
Hawliau Cyffredinol / General rights

Copyright and moral rights for the publications made accessible in the public portal are retained by the authors and/or other copyright owners and it is a condition of accessing publications that users recognise and abide by the legal requirements associated with these rights.

- Users may download and print one copy of any publication from the public portal for the purpose of private study or research.

- You may not further distribute the material or use it for any profit-making activity or commercial gain

- You may freely distribute the URL identifying the publication in the public portal ?
}

Take down policy

If you believe that this document breaches copyright please contact us providing details, and we will remove access to the work immediately and investigate your claim. 
This research was accepted in its current form for publication in Anxiety, Stress, and Coping on 27.08.2017

\section{Changing performance pressure between training and competition}

2 influences action planning because of a reduction in the efficiency of action

3 execution.

4 Victoria E. Cassell

5 Stuart J. Beattie

6 Gavin P. Lawrence

7 School of Sport, Health and Exercise Sciences, Institute for the Psychology of Elite

8 Performance, Bangor University

9 Corresponding Author: $\quad$ Dr Gavin Lawrence

School of Sport, Health and Exercise Sciences,

Institute for the Psychology of Elite Performance,

Bangor University,

George Building,

Holyhead Road,

Bangor,

Gwynedd.

E-mail: g.p.lawrence@bangor.ac.uk

Tel: $\quad+44(0) 1248388283$

Web: http://www.bangor.ac.uk/sport/staff-gl.php 
This research was accepted in its current form for publication in Anxiety, Stress, and Coping on 21.09.2017

\section{Changing performance pressure between training and competition}

3 influences action planning because of a reduction in the efficiency of action execution.

Background and objectives: Specificity of practice proposes optimal performance is linked to the conditions under which learning occurred. The present study investigated this effect within a pressure context to determine whether offline and/or online control processes develop specificity through the introduction or removal of performance pressure. Methods: 40 novices practiced a two-dimensional stimulus-response discrimination task in one of four groups; two control (control-control and anxietyanxiety) and two experimental (control-anxiety and anxiety-control). In the experimental groups, participants experienced a switch in conditions of pressure both early and late in practice i.e., practiced in low-pressure and transferred to high-pressure (control-anxiety group) or the reverse of this (anxiety-control group). Results: A significant acquisition-to-transfer decrement in performance occurred for both experimental groups. This offers support for a pressure-performance specificity effect, because a change in conditions of pressure (regardless if that was an increase or decrease) resulted in performance decrements. Furthermore, the reaction time measure of offline control was affected by the change to a significantly greater extent than the movement time measure of online control. Conclusions: Increases in offline control processes was a performance strategy adopted to combat the disruption that pressure caused to the processes associated with adjusting or planning movements online.

Keywords: specificity of practice; pressure; anxiety; offline control processes; online control processes 
This research was accepted in its current form for publication in Anxiety, Stress, and Coping on 21.09.2017

3 Changing performance pressure between training and competition

4 influences action planning because of a reduction in the efficiency of action

5 execution and adjustment.

6

7
Optimal performance is more often than not the goal of athletes, particularly when rewards are high. However, in pressure situations many athletes perform sub optimally despite high motivation to succeed (Baumeister \& Showers, 1986). Within the field of sport psychology, this specific negative response to perceived pressure (Beilock \& Gray, 2007) has been termed 'choking'. Recent literature has revealed that the choking phenomenon can be eliminated if performers practice under anxious conditions prior to performing under pressure situations (Nieuwenhuys \& Oudejans, 2010; Oudejans \& Pijpers, 2009) with Lawrence, Cassell, Beattie, Woodman, Khan et al., (2014) providing direct experimental evidence that these effects conform to the principles of Specificity of Practice (Proteau, 1992). That is, movement plans are adapted to the performer's mood state during practice, in this case anxiety, and performance between practice and subsequent testing is maintained only if the conditions of anxiety between these two phases remain constant. Furthermore, there is also an anxiety exposure effect. Specifically, the more practice one receives under a particular anxiety state, the stronger the dependency on that anxiety state for successful performance (Lawrence et al., 2014). Whilst, Lawrence et al.'s (2014) experiments provide robust evidence for the specificity effect within the domain of anxiety, they only investigate outcome measures of performance. Thus, the purpose of the present experiment was to examine the aspects of motor control that develop specificity to an anxiety mood state i.e., the 
This research was accepted in its current form for publication in Anxiety, Stress, and Coping on 21.09.2017

1 strategies surrounding the pre-planning of movement parameters (i.e., offline control) and/or

2 the strategies associated with planning and/or adjusting parameters during movement

3 execution (i.e., online control).

4

Recent attempts to address this research lacuna have been conducted by Coombes,

5 Higgins, Gamble, Cauraugh, \& Jannell (2009) and Lawrence, Khan, and Hardy (2012). In

6 order to investigate the effects of anxiety on movement planning (offline processes),

7 Coombes et al. (2009) utilised an open loop pre-planned target force contraction task.

8 Specifically, the task consisted of a pinch action with the index and thumb digits under no

9 vision conditions and participants were required to produce a variety of forces relative to their

10 maximal voluntary force production. The task was adopted to measure movement planning

11 efficiency (reaction time [RT] and rate of force change) and performance efficiency (RMSE

12 of actual force production) in both high and low anxious individuals. Conversely, Lawrence

13 et al. (2012) utilised visuomotor tasks in order to measure the concurrent effects of anxiety on

14 both offline and online movement control. Here participants were required to make full

15 vision upper limb pointing movements in criterion movement times (MT) ( 400 ms)

16 sufficient to allow the use of afferent information during movement execution (i.e., online).

17 Variability in movement trajectories were compared between high and low anxiety conditions

18 in order to infer online and offline control processes (for a review see Khan, Franks, Elliott,

19 Lawrence, Chua, Bernier, et al., 2006). The results of Coombes et al. (2009) revealed that

20 movement planning (RT and rate of force change) was compromised by anxiety in the more

21 cognitively difficult task requiring greater working memory (i.e., reproducing $10 \%$ of

22 maximal voluntary force production). In contrast, Lawrence et al. (2012) revealed that

23 anxiety negatively affected the use of afferent information to adjust movement trajectories 
This research was accepted in its current form for publication in Anxiety, Stress, and Coping on 21.09.2017

1 online but did not negatively affect the offline processing of afferent information when

2 planning a trajectory's initial direction and accuracy.

3

The equivocal findings of Coombes et al. (2009) and Lawrence et al. (2012) can be

4 attributed to both the theoretical underpinnings used to explain the findings together with the

5 lack of measurements used to investigate online control processes within Coombes et al.'s

6 (2009) research design. That is, when investigating offline processes only, Coombes et al.

7 (2009) applied the principles of Eysenck, Derakshan, Santos, \& Calvo's (2007) attentional

8 control theory to interpret their findings. Specifically, Coombes et al. (2009) proposed that

9 anxiety affected the central executive component of working memory by reducing the

10 participants' ability to inhibit interference from task-irrelevant cues and maintain focus on the

11 task. This reduced inhibition and shift in focus lead to a decrease in the resources available

12 for the task, ultimately resulting in a reduction in the efficiency of the systems offline control

13 processes in the more difficult (i.e., cognitive resource intensive) force production task.

Because online movement adjustments are said to be reflexive in nature and not under

conscious, effortful control (for an example see Briere \& Proteau, 2011), Lawrence et al.

16 (2012) used the principles of reinvestment hypothesis (Masters, 1992) to explain their

17 findings. They proposed that anxiety led to increases in self-awareness which caused

18 participants to 'reinvest' in previously learnt (or developed) rules about how to perform the

19 task. The act of reinvestment lead to a breakdown of the normally automatic online

movement correction processes resulting in a reduction in performance associated with online

21 control. Since Coombes et al. (2009) did not include measures of online control processes,

22 one cannot be certain that the changes they observed in the efficiency of the offline control

23 processes were because of a direct result of anxiety or because of the strategies adopted by 
This research was accepted in its current form for publication in Anxiety, Stress, and Coping on 21.09.2017

1 participants in order to combat the effects of anxiety on online movement adjustment

2 processes. Specifically, participants might have planned movements more accurately because

3 anxiety reduced the systems effectiveness to make adjustments to response plans during

4 movement execution.

When interpreting the findings of both Coombes et al. (2009) and Lawrence et al.

6 (2012), the specificity of practice effect supported by Lawrence et al. (2014) could provide an

7 alternative explanation to that of attentional control theory (Eysenck et al., 2007) and

8 reinvestment (Masters, 1992). That is, participants who practiced under control conditions

9 may have developed movement strategies specific to both the information and the anxiety

10 state that was present during practice. Therefore, when conditions changed during transfer

11 (i.e., addition of anxiety) both the information that was available and the anxiety state altered.

12 This incongruity between acquisition and transfer would lead to the movement plan/strategies

13 that were developed in practice (i.e., in the control condition) no longer being adequate for

14 successful performance. However, even with the addition of this possible specificity

15 explanation, the research design of both Coombes et al. (2009) and Lawrence et al. (2012) do

16 not directly allow one to infer the specificity effect of anxiety, or to investigate whether it is

17 either (or a combination of), offline and online motor processes that develop specificity to an

18 anxious mood state.

19 In the present investigation we were interested in extending the specificity of learning

20 research within the psychological construct of anxiety by investigating both the pre-planning

21 of movement parameters (i.e., offline control) and the planning, adjustment, or

22 implementation of pre-planned parameters during movement execution (i.e., online control).

23 Specifically we asked participants to make a series of complex upper limb movement patterns 
This research was accepted in its current form for publication in Anxiety, Stress, and Coping on 21.09.2017

1 in either a control or pressured learning environment before transferring them to the opposite

2 condition. The aim of the complex movement pattern allowed performance to be separated

3 into variables associated with offline (e.g., RT, Henry \& Rogers, 1960; Khan, Lawrence,

4 Buckloz, \& Franks, 2006) and online control (e.g., MT, Khan et al., 2006 ; Khan, et al.,

$5 \quad 2006^{\mathrm{b}}$ ). Parsing movement responses in this way enabled the investigation into what aspects

6 of motor control (offline and/or online control) develop specificity when training under

7 conditions of anxiety and control. It is important to note here that the aim was to investigate

8 the specificity effects on offline and online control processes rather than the effect on explicit

9 mechanisms within each process. That is, we aimed to investigate the holistic processes

10 involved in the motor system before movement (i.e., planning or offline) and during

11 movement (i.e., execution or online) via the use of RT and MT measures.

The distinction between using these measures to infer holistic offline and online control processes rather than specific mechanisms within each process is important for a number of reasons. Firstly, planning is proposed to involve the selection of an appropriate response based on information from the environment and actor via conscious, effortful and non automatic parameterisation of movement, and typical occurs before movement execution

17 (Beilock, Jellison, Rydell, McConnell, \& Carr, 2006, Schmidt, Zelaznik, Hawkins, Frank, \& 18 Quinn 1979). Whilst research indicates that planning of movement parameters is reflected in 19 RT (Chamberlain \& Magill, 1989; Henry \& Rogers, 1960; Klapp, 1995, 2003, Khan, et al.,

$202006^{\mathrm{b}}$ ), the previously highlighted definition of planning adopted from the research of

21 Beilock et al., (2006) and Schmidt et al., (1979) indicates that planning only typically occurs

22 before movement execution. Indeed, past literature provides evidence that movement

23 planning can occur during execution and thus is not always reflected in measures of RT 
This research was accepted in its current form for publication in Anxiety, Stress, and Coping on 21.09.2017

1 (Henry \& Rogers, 1960; Khan et al., 2006 ${ }^{\mathrm{b}}$ ). As a result (and to ensure our measure of RT is

2 not taken purely as an indication of movement planning), we use RT as an holistic measure of

3 offline processes rather than a measurement of the explicit mechanism of planning.

4

We are being similarly cautious not to associate our measure of MT with any explicit

5 online error correction mechanism. Firstly, because we have already indicated above that

6 movement planning can occur online and would be reflected in changes to MT. But also,

7 because online error correction mechanisms are said to be based on automatic and reflexive

8 processing of afferent information which may or may not be reflected in changes to MT

9 (Briere \& Proteau, 2011; Khan et al., 2006 ${ }^{\mathrm{b}}$ ). Whilst such online processes may not be

10 captured in our measure of MT, research investigating the integration of multiple target

11 actions has revealed increases in MT associated with online control processes that centre

12 around timing the implementation and/or controlling the accuracy of actions (e.g., the

13 movement integration hypothesis of Adam, Nieuwenstein, Huys, Paas, Kingma, Willems, \&

14 Werry; 2000 and the movement constraint hypothesis of Fishman \& Reeve (1992). Therefore,

15 because research indicates that MTreflects a number of (but not all) possible online control

16 processes, and that RT cannot be used to infer all movement planning processes, it is beyond

17 the scope of the current study to investigate precisely which offline and/or online processes

18 develop specificity to anxiety. Rather we are using the measure of RT and MT to further the

19 performance outcome measures of Lawrence et al. (2014) by measuring the holistic processes

20 associated with motor control both prior to movement execution (i.e., offline) and during

21 movement execution (i.e., online).

22 Hypotheses 
This research was accepted in its current form for publication in Anxiety, Stress, and Coping on 21.09.2017

Based on the specificity findings of Lawrence et al. (2014), we hypothesised that

2 performance decrements would occur in both the control and anxiety training groups when

3 there was a switch in anxiety state between acquisition and transfer. Furthermore, in line

4 with Lawrence et al., (2014), and previous goal directed aiming specificity literature (Proteau

5 \& Cournoyer, 1990; Proteau \& Marteniuk, 1993; Proteau, Marteniuk, Girouard, \& Dugas,

6 1987), we expected these specificity performance decrements to get larger as a function of

7 practice/exposure. That is, as practice increases, the movement plans/strategies associated

8 with successful performance establish greater links with the particular state of anxiety during

9 practice. Thus, the later in practice one experiences a change in the conditions of anxiety, the

10 greater the (specificity) effect on performance. Therefore, we hypothesised that changes in

11 conditions (anxiety) would only result in performance decrements in our late transfer tests.

12 In regards to where in the motor control system these performance decrements occur, we

13 hypothesised (based on the findings of Coombes et al., 2009), that offline processes (i.e., pre-

14 planning of movement) would take longer following a switch to anxiety resulting in an

15 increase in our RT measure. However, given that recent research indicates that anxiety

16 reduces one's ability to utilise online control processes (Lawrence et al., 2012), it was

17 hypothesised that the increased RT would be accompanied by reduced execution times i.e.,

18 our MT measure. Thus, we hypothesised that the presence of anxiety would reduce the

19 effectiveness of online processes resulting in faster MTs. Participants would attempt to

20 control for this by spending longer planning their movements (slowing down RT) in order to

21 avoid online movement planning and/or adjustment for successful performance. 
This research was accepted in its current form for publication in Anxiety, Stress, and Coping on 21.09.2017

\section{Method}

\section{Participants}

3 Forty participants (17 male, 23 female; mean age $=24.07, S D=7.05)$ with no previous

4 experience in the experimental task, volunteered to participate in the study. All participants

5 were naive to the hypotheses tested and gave their written informed consent prior to taking

6 part in the study. The experiment was conducted in accordance with the guidelines of the

7 ethics committee of the School of Sport, Health and Exercise Sciences, Bangor University for

8 research involving human participants. The committee guidelines are in line with the 1964

9 Helsinki declaration and its later amendments or comparable ethical standards.

10 Apparatus

11 Participants held a digitising pen with their right hand and made movements on a

12 Calcomp III digitizing tablet $($ size $=1220 \mathrm{~cm} \times 915 \mathrm{~mm}$, sample rate $=200 \mathrm{~Hz}$, accuracy $= \pm$

$130.125 \mathrm{~mm}$ ) positioned horizontally in front of them. The position of the pen was represented

14 by a cursor ( $1 \mathrm{~cm}$ in diameter) on a 37" Mitsubishi Diamond Pro computer monitor (refresh

15 rate $=85 \mathrm{~Hz}$ ) situated $400 \mathrm{~mm}$ in front of the participants and $200 \mathrm{~mm}$ above the tablet. Visual

16 displays of the start position, target regions, and a cursor representing the pen position

17 appeared on the monitor screen (see Figure 1) and remained visible for the duration of the

18 experiment. Movements of the pen away from the participant's body on the tablet

19 corresponded to vertical movements of the cursor on the monitor. There was a one to one

20 mapping (in $\mathrm{mm}$ ) between the movement of the pen and the movement of the cursor. All

21 target regions consisted of a white circle (40mm in diameter) positioned equally in a $3 \times 3$

22 grid formation within a $200 \mathrm{~mm} \times 200 \mathrm{~mm}$ area. The start position consisted of a green circle

23 (40mm in diameter) and was located in the centre position on the bottom row of the $3 \times 3$ 
This research was accepted in its current form for publication in Anxiety, Stress, and Coping on 21.09.2017

1 grid (see Figure 1). The participants chair was adjustable in height so that the participant's

2 eyes were at a level with the middle of the $200 \mathrm{~mm} \times 200 \mathrm{~mm}$ target area. The participant's

3 arm and hand were hidden from view by an opaque shield thus preventing direct vision of the

$4 \quad$ limb throughout testing.

\section{$5 \quad$ Task and Procedure}

At the start of testing, we informed participants that the aim of the experiment was to

7 investigate the accuracy and timing of their movement, and that movement should be

8 performed as quickly, smoothly, and accurately as possible. We told participants that they

9 would be performing a series of three different aiming movement tasks, each of which

10 followed specific movement pathways. They were also made explicitly aware that each task

11 required three targets to be hit, but the movement sequence between targets differed

12 depending on which stimulus was presented (see Figure 1) ${ }^{1}$. Specifically, at the start of each

13 trial, participants were presented with a tone that required them to 'get ready'. Following a

14 variable (1500-2500 ms) foreperiod, the stimulus appeared which consisted of one of the

15 targets from the top line changing colour from white to red; the change in colour of either the

16 top left, top middle, or top right target were the stimuli informing the participants to execute

17 pattern 1, 2 or 3, respectively (see Figure 1). Following the stimulus, participants were required to respond as fast as possible and complete the required movement pattern as

\footnotetext{
${ }^{1}$ To control for potential speed accuracy trade-offs, participants were required to hit each of the three targets in each of the different movement sequences. Failure to do so resulted in deletion of that data trial from analyses (this equated to less than $3 \%$ of trials in any one participant).
} 
This research was accepted in its current form for publication in Anxiety, Stress, and Coping on 21.09.2017

1 smoothly ${ }^{2}$, quickly, and accurately as they could before coming to a complete stop upon

2 reaching the stimulus target (see Figure 1).

Participants completed a total of 603 trials. The first 27 trials were performed with the

4 assistance of a schematic of the three to-be-learned patterns. This was to familiarise participants with the movement of each pattern. The remaining trials (i.e., 576 trials) were randomised between the three tasks, distributed into an acquisition phase (18 blocks of 30 trials) and two transfer tests ( 2 blocks of 18 trials), and were administered over a 3 day period. Each block contained an equal number of presentations of each movement task and was randomised such that none of the three tasks was repeated before each task had been presented. This pseudo-randomisation procedure differed between participants so that whilst the number of tasks was always equal within each block, the order of these was different for each participant.

To start, participants completed block 1 (day 1) which consisted of 27 trials (9 in each task) before being given a 5-minute break followed by the early transfer block (day 1), which consisted of 18 trials (6 in each task). After a further 5-minute break, the acquisition phase continued with a total of 180 trials in the form of 6 blocks of 30 trials (10 in each task). Block 1, early transfer and the first acquisition phase (blocks 2-7) were all conducted on day 1. The following day consisted of an acquisition phase that was identical to that of the

\footnotetext{
${ }^{2}$ The instructions to move as smoothly as possible were to reduce the potential of discrete adjustments during movement trajectories and rather encourage continuous online trajectory control. This strategy has been used in the past (see Khan \& Lawrence, 2005; Khan, Lawrence, Buckloz, \& Franks, 2006; Khan, Lawrence, Franks, and Buckloz, 2004; Lawrence, Khan, Buckloz, \& Oldham, 2006; Lawrence, Khan, Mourton, \& Bernier, 2011) in order to prevent noise in the data when equating movement start and stop positions from temporal changes in velocity after first locating peak velocity. That is, in situations where peak velocity occurs in the second 'discrete' movement adjustment phase of the trajectory, start position and movement time would be inaccurate.
} 
This research was accepted in its current form for publication in Anxiety, Stress, and Coping on 21.09.2017

1 previous day i.e., participants completed 180 trials in the form of 6 blocks of 30 trials (10 in

2 each task). On the final day, participants completed another 6 blocks of 30 acquisition trials,

3 before completing the late transfer phase. The late transfer phase was identical to that of the

4 early transfer in that participants completed a block of 18 trials ( 6 in each task). Consistent

5 with day 1 , participants received a 5-minute break before completing the late transfer test.

Such that each group contained 10 participants, each of the 40 participants was quasi-

7 randomly assigned (using a freely available online randomisation programme - random.org)

8 to one of four groups. In the control-control group, all acquisition and transfer trials were

9 performed under normal (low anxiety) conditions. In the anxiety-anxiety group, all

10 acquisition and transfer trials were performed under anxiety conditions. In the control-

11 anxiety group, acquisition trials were performed under normal (low anxiety) conditions and

12 both the early and late transfer tests under anxiety conditions. Finally, in the anxiety-control

13 group, participants followed the same procedure to that of the control-anxiety group with the exception that the order of the anxiety and the control conditions were reversed.

\section{Anxiety Manipulation}

We manipulated anxiety through a combination of intrinsic and extrinsic competition.

17 In acquisition, participants were informed that their movements were being video recorded

18 for analysis by researchers within the University. We also told participants that the person

19 with the best combined RTs and MTs would win $£ 100$ and there were both a winners and

20 losers board presented in the room representing the results for every participant to see.

21 Further to this, participants were also subjected to a new 'experiment observer' during the

22 anxiety transfer phases. This experimenter stood behind the participant and pretended to

23 make notations regarding their movement patterns. Finally, during the anxiety transfer phase 
This research was accepted in its current form for publication in Anxiety, Stress, and Coping on 21.09.2017

1 in addition to the $£ 100$ that could already be won during acquisition, it was made clear to

2 participants that they had been partnered with another individual, and that in order for them to

3 secure the prize money (now $£ 200$; $£ 100$ per person), both them and their partner needed to

4 achieve a $20 \%$ improvement in their combined RT and MT performance. We then informed

5 participants that their partners had already completed the experiment and successfully

6 achieved the required 20\% improvement. All participants were told they would receive an

7 email detailing who they were partnered with and how that individual had performed ${ }^{3}$.

In order to ensure the measure of cognitive anxiety had been successfully

9 manipulated, all participants completed the mental readiness form-3 (MRF-3) (Krane, 1994)

10 immediately prior to the start of the first block of acquisition trials on day 1; early transfer;

11 the second block of acquisition trials on day 1 ; the first block of acquisition trials on day 2 ;

12 the first block of acquisition trials on day 3; and late transfer. The MRF-3 comprises of three

13 single item factors that are each scored on an 11 point Likert scale: cognitive anxiety from 1

14 (not worried) to 11 (worried); somatic anxiety from 1 (not tense) to 11 (tense); and self-

15 confidence from 1 (confident) to 11 (not confident) ${ }^{4}$. Effort, as measured via the Rating

16 Scale of Mental Effort (RSME; Zijlstra,1993) was measured retrospectively (i.e.,

17 immediately post block) at the same experimental phases.

\footnotetext{
${ }^{3}$ The actual sole determinant of monetary reward (£100) in acquisition was the participant with the highest combined performance score. The sole determinant of monetary award (£100) in transfer was determined by whether the participant increased performance above the criterion $20 \%$; all other manipulations were part of the ethically approved anxiety deception.

${ }^{4}$ For the purpose of the present study and keeping in line with previous research (Coombes et al. 2009; Lawrence et al. 2012; 2014) only the cognitive anxiety scale was used to assess anxiety levels.
} 
This research was accepted in its current form for publication in Anxiety, Stress, and Coping on 21.09.2017

\section{Data Reduction and Performance Measures}

The position data for each trial were filtered using a second-order dual-pass

3 Butterworth filter with a low-pass cut-off frequency of $10 \mathrm{~Hz}$. Instantaneous velocity data

4 were obtained by differentiating the position data using a two-point central finite difference

5 algorithm. To obtain movement kinematics, we adopted the methods of previous video-

6 aiming target directed literature (Briere \& Proteau, 2011; Khan, Lawrence, Franks, and

7 Buckloz, 2004; Lawrence, Khan, Buckloz, \& Oldham, 2006; Lawrence, Khan, Mourton, \&

8 Bernier, 2011). Specifically, to locate the beginning of the movement, peak velocity was first

9 obtained. The velocity profile was then traversed backwards in time until the velocity fell

10 below $15 \mathrm{~mm} / \mathrm{sec}$. The end of the movement to the first target was defined as the first point in

11 time following peak velocity in which the absolute angular velocity of the pen fell below

$1215 \mathrm{~mm} / \mathrm{sec}$. This process was repeated to locate the start and end of the second and third

13 movements, respectively. If the absolute velocity between the end of one movement and the

14 beginning of the next movement remained below $15 \mathrm{~mm} / \mathrm{sec}$, the movement was said to

15 contain a pause. Pause time was then calculated as the interval between the end of one

16 movement and the start of the subsequent movement ${ }^{5}$.

17 Analysis

18 Early Transfer and Late Transfer. Whilst performance data was collected throughout all 603

19 trials, to avoid the possibility of inflating type 1 error we only analysed data at the

20 hypothesised time points of interest. Similarly, to reduce test-wise error the number of

21 statistical tests conducted was minimised by combining the times of each response movement

\footnotetext{
${ }^{5}$ The parsing of movements to include pause time, was in line with the motor planning literature proposals that pause time might be reflective of online planning processes $\left(\right.$ Khan $\left.2006^{\mathrm{b}}\right)$.
} 
This research was accepted in its current form for publication in Anxiety, Stress, and Coping on 21.09.2017

1 (MT1, MT2, and MT3) into a single overall MT measure for each trial. Furthermore, since

2 our MT and pause time measures were both attributed to processes occurring during response

3 execution (online), we report only our MT measure ${ }^{6}$. Therefore, primary performance data

4 consisted of RT and overall MT (OMT). RT was the interval from the presentation of the

5 stimulus to the start of movement. OMT was the sum of the MTs for the three movements in

6 each response. To investigate our hypothesised effects at early transfer, the anxiety (MRF-3)

7 and effort measures (RSME) and the different performance measures (RT and OMT) were

8 individually submitted to separate 4 (group: control-control; anxiety-anxiety; control-anxiety;

9 anxiety-control $) \times 2$ (experimental phase: block 1 day 1 ; early transfer) ANOVA with

10 repeated measures on the second factor. The same measures were further submitted to

11 separate 4 (group: control-control; anxiety-anxiety; control-anxiety; anxiety-control) $\times 2$

12 (experimental phase: last block of acquisition [block 6 day 3]; late transfer) ANOVAs with

13 repeated measures on the second factor, to assess late transfer effects. Statistical significance

14 was defined a priori as alpha level <.05 and corrections were applied following any

15 violations to Sphericity using Greenhouse-Geisser adjustments. All significant effects were

16 broken down using Tukey's HSD post hoc procedures $(p<.05)$.

17 Results

18 Early Transfer

Anxiety and Effort measures. As shown in Figure 2 (panel a), the analysis of the

MRF-3 data revealed a non-significant main effect of experimental phase $\left(\mathrm{F}_{(1,36)}=.147, p=\right.$

$21.68)$, a significant main effect of group $\left(\mathrm{F}_{(3,36)}=4.07, p=.01, \omega^{2}=.19\right)$, and a significant

\footnotetext{
${ }^{6}$ Separate analyses (identical to those of the primary dependant variables) were conducted for MT1, MT2, MT3, pause time 1 , and pause time 2 post the primary analyses reported in the manuscript. All these separate online processing variables revealed the same significant pattern of results as our overall MT measure.
} 
This research was accepted in its current form for publication in Anxiety, Stress, and Coping on 21.09.2017

1 experimental phase $\mathrm{x}$ group interaction $\left(\mathrm{F}_{(3,36)}=3.59, p=.02, \omega^{2}=.16\right)$. As expected,

2 breakdown of this interaction revealed that the anxiety manipulation was successful where

3 targeted. That is, MRF-3 score significantly increased from the first block of acquisition to

4 early transfer for the control-anxiety group and significantly decreased for the anxiety-control

5 group (no significant changes were observed for the control-control or the anxiety-anxiety

6 groups). Furthermore, the different methods for manipulating anxiety between acquisition

7 and transfer appear comparative since the MRF-3 levels reported in both the acquisition and

8 transfer anxiety manipulations were not significantly different from one another. The

9 analysis of the RSME revealed no significant main effects or interactions (experimental phase

$10\left[\mathrm{~F}_{(1,36)}=.75, p=.79\right]$; group $\left[\mathrm{F}_{(3,36)}=1.06, p=.38\right]$ experimental phase $\times$ group interaction

$\left.11\left[\mathrm{~F}_{(3,36)}=.95, p=.95\right]\right)($ see Figure 2 panel a).

Performance Measures; RT (offline processes). As shown Figure 2 (panel a), the analysis of RT revealed non-significant main effects for experimental phase and group $\left(\mathrm{F}_{(1,36)}\right.$

$14=.41, p=.53$ and $\mathrm{F}_{(3,36)}=2.50, p=.08$, respectively), but did reveal the hypothesied significant experimental phase $\times$ group interaction $\left(\mathrm{F}_{(3,36)}=3.45, p=.02, \omega^{2}=.16\right)$.

Breakdown indicated that the anxiety-control and control-anxiety groups experienced a significant slowing of RT from the first block of acquisition (block 1 day 1) to early transfer (i.e., a change in practice conditions resulted in a significant decrement in performance). Whereas, the performance in the control-control and anxiety-anxiety group significantly increased (RTs got significantly faster) from first block of acquisition (block 1 day 1) to early 21 transfer.

Performance Measures; Overall Movement time (online processes). As shown in

23 Figure 2 (panel a), Overall MT data revealed only a significant main effect for experimental 
This research was accepted in its current form for publication in Anxiety, Stress, and Coping on 21.09.2017

1 phase $\left(\mathrm{F}_{(1,36)}=25.40, p=.001, \omega^{2}=.39\right)$ with performance significantly increasing (MTs got

2 faster) from the first block of acquisition to early transfer. The main effect for group $\left(\mathrm{F}_{(3,36)}\right.$

$3=1.08, p=.37)$, together with the experimental phase $\times$ group interaction $\left(\mathrm{F}_{(3,36)}=1.33, p=\right.$

$4 \quad .28)$ were non-significant.

\section{$5 \quad$ Late Transfer}

Anxiety and Effort measures. As shown in Figure 2 (panel b), the analysis of the

7 MRF-3 data revealed a non-significant main effect of experimental phase $\left(\mathrm{F}_{(1,36)}=2.61, p=\right.$

$8.12)$, a significant main effect of group $\left(\mathrm{F}_{(3,36)}=24.65, p=.001, \omega^{2}=.64\right)$, and a significant

9 experimental phase $\times$ group interaction $\left(\mathrm{F}_{(3,36)}=21.92, p=.001, \omega^{2}=.61\right)$. As expected,

breakdown of this interaction revealed that the MRF-3 score significantly increased between

the last block of acquisition and late transfer for the control-anxiety group and significantly

decreased for the anxiety-control group (no significant changes were observed for the

control-control or the anxiety-anxiety groups). Furthermore, the different methods for

manipulating anxiety between acquisition and transfer appear comparative since the MRF-3

levels reported in both the acquisition and transfer anxiety manipulations were not

significantly different from one another. The analysis of the RSME revealed no significant main effects or interactions (experimental phase $\left[\mathrm{F}_{(1,36)}=1.82, p=.19\right]$; group $\left[\mathrm{F}_{(3,36)}=1.71\right.$, $p=.18]$ experimental phase $\times$ group interaction $\left.\left[\mathrm{F}_{(3,36)}=.24, p=.87\right]\right)$ (see Figure 2 panel $\mathrm{b}$ ).

effect of experimental phase $\left(\mathrm{F}_{(1,36)}=7.42, p=.01, \omega^{2}=.14\right)$, a non-significant main effect of group $\left(\mathrm{F}_{(3,36)}=1.17, p=.34\right)$, and a significant experimental phase $\times$ group interaction $\left(\mathrm{F}_{(3,36)}=7.98, p=.001, \omega^{2}=.34\right)$. As hypothesised breakdown of this interaction revealed that whilst performance in the control-control and anxiety-anxiety group did not significantly 
This research was accepted in its current form for publication in Anxiety, Stress, and Coping on 21.09.2017

1 differ between acquisition and transfer, the anxiety-control and control-anxiety groups did

2 reveal significant decreases in performance (RT got significantly slower) between acquisition 3 and late transfer (see Figure 2 panel b).

5 Figure 2 (panel b), analysis of MT revealed a significant main effect for experimental phase

$6 \quad\left(\mathrm{~F}_{(1,36)}=4.48, p=.04, \omega^{2}=.08\right)$, a non-significant main effect of group $\left(\mathrm{F}_{(3,36)}=.49, p=\right.$

$7.70)$, and a significant experimental phase $\times$ group interaction $\left(F_{(3,36)}=3.66, p=.02, \omega^{2}=\right.$

8 .17). Breakdown of the interaction indicated that a change in practice conditions resulted in

9 significantly longer MTs for the anxiety-control group, but not for the control-anxiety,

10 control-control and anxiety-anxiety groups (see Figure 2 panel b).

11 Early versus late transfer.

Our measure of offline processes (RT) revealed specificity effects at both early and late transfer. In order to investigate the hypothesised specificity exposure effect, we performed separate (Bonferroni corrected) paired samples t-tests (one on control-anxiety data and the other on anxiety-control data) to compare the differences in the size of the performance decrement (RT increase) at early and late transfer. We then also conducted a

17 further independent samples t-test (control-anxiety versus anxiety-control group) on the within group calculated difference between the increases in RT at early compared to late transfer. The results of all three tests revealed no significant mean differences $\left(t_{9}=0.85, p=\right.$ $0.93 ; t_{9}=-0.60, p=0.56 ; t_{18}=0.58, p=0.57$, respectively).

\section{Discussion}

22 Summary

23 The purpose of the current experiment was to examine Lawrence et al.,'s (2014) anxiety- 
This research was accepted in its current form for publication in Anxiety, Stress, and Coping on 21.09.2017

1 performance specificity effects within the psychological construct of anxiety with particular

2 reference to examining what aspects of motor control develop specificity. Dependent

3 measures included both offline control (as measured by RT) and online control (as measured

4 by MT). As expected, results revealed that the anxiety manipulation was successful where

5 targeted and that task effort was similar for all groups. The change in anxiety between

6 acquisition and transfer (regardless if that change was an increase or decrease in anxiety)

7 resulted in significant changes in RT and MT. However, these anxiety-performance

8 specificity observations were reflected in strategies associated with offline control processes

9 to a greater extent than the online control processes.

10 Anxiety-performance specificity

11 In line with our hypothesis, we observed an anxiety-performance specificity effect.

12 That is, task performance significantly decreased for the groups that experienced a change in

13 the anxiety conditions between acquisition and transfer (control-anxiety and anxiety-control)

14 but did not change significantly for the groups where anxiety conditions were designed to

15 remain constant between these experimental phases (control-control and anxiety-anxiety).

16 Indeed, the latter two groups continued to see an improvement in performance at early

17 transfer suggesting that our experimental task was novel enough to produce learning effects.

18 Furthermore, it appears that these increases in task performance reached levels of asymptote

19 before the end of the acquisition phase because no significant performance improvements

20 were observed in the control-control or the anxiety-anxiety groups between the end of

21 acquisition and late transfer. However, in line with Lawrence et al., (2014), we propose that

22 the change in anxiety in the control-anxiety and anxiety-control groups between acquisition

23 and transfer and the subsequent decrease in performance between these experimental phases

24 is supportive of anxiety-performance specificity and the existence of a performance based 
This research was accepted in its current form for publication in Anxiety, Stress, and Coping on 21.09.2017

1 network theory of affect (Gilligan \& Bower, 1983). Specifically, our pattern of data suggest

2 that the best learning experiences are those that most closely approximate the movements of

3 the target skill and the environmental conditions of the target context. Therefore, similar to

4 research within the sensory domain (Khan \& Franks, 2000; Mackrous \& Proteau, 2007) we

5 propose that participants developed a movement strategy to optimise the information

6 available under their particular anxiety state during acquisition and that this movement

7 strategy was specific to the anxiety state that was available during practice. Hence, when the

8 anxiety during practice and transfer were changed, the movement strategies previously

9 developed were no longer appropriate for successful performance.

Similarly, the network theory of affect (Gilligan and Bower, 1983) indicates that

11 learning is enhanced when there is high congruity between a learner's mood state during

12 acquisition and subsequent recall. Here, mood state is regarded as a unit within a semantic

13 network that connects internalised related events. The activation of a unit results in a

14 spreading of this activation through the network to related units. As such, associations are

15 formed between units relating to that which needs to be learned and the unit activated due to

16 the learner's mood state. When the learner is required to recall what was learned, the mood

17 state at that time leads to the activation of the appropriate mood unit and subsequently to

18 those units associated with it. If there is a match between mood at learning and mood at the

19 time of recall, then the activation of the units of what is to be remembered is increased and

20 recall is enhanced (Bower, Monteiro, \& Gilligan, 1978; Schare, Lisman, \& Spear, 1984).

21 The research of Bower et al., (1978), Gilligan and Bower (1983), and Schare et al., (1984)

22 utilised 'non-movement' memory recall tasks (e.g., memorising and recalling a list of words)

23 when demonstrating the network theory of affect. Both the present study and the experiments 
This research was accepted in its current form for publication in Anxiety, Stress, and Coping on 21.09.2017

1 of Lawrence et al., (2014) utilised a gross motor skill to demonstrate the anxiety -

2 performance specificity effect. Thus, we propose that Gilligan and Bower's (1983) network

3 theory of affect is not limited to a semantic network that includes only units associated with

4 recall of internalised (non-movement) related events. Rather, our data presents evidence that

5 the network theory of affect be extended to contain a semantic network that also includes

6 units associated with recall of muscular patterns and movements.

$7 \quad$ Anxiety-performance specificity effects; offline versus online control strategies

In regards to where in the motor control system one would observe the anxiety performance specificity effect, we hypothesised (based on the findings of Coombes et al., 2009), that the pre-planning of movements (RT) would take longer under conditions of anxiety. However, given that anxiety influences the effectiveness of adjustments to movement trajectories during execution (Lawrence et al., 2012) it was also hypothesised that the increased RT would be accompanied by reduced execution times (MT). That is, the presence of anxiety would reduce the effectiveness of online movement adjustment (in comparison to low anxiety conditions) and thus participants would attempt to control for this by spending longer planning their movements to ensure trajectories did not require further planning and/or online adjustment for successful performance ${ }^{7}$.

The RT data indicated that the anxiety-performance specificity effect resulted in longer RTs (assumed to be indicative of longer time spent pre-planning movement parameters) for both the control-anxiety and anxiety-control groups. Furthermore, this effect

${ }^{7}$ MT was used as a holistic measure of online processes (i.e., possible online planning, adjustments to movements during execution, and timing the accurate implementation of pre-planned movements) and thus, may not be completely or solely reflective of online trajectory adjustment processes. 
This research was accepted in its current form for publication in Anxiety, Stress, and Coping on 21.09.2017

1 was observed at both early (see Figure 2a) and late transfer (see Figure 2b). Research

2 investigating specificity effects of afferent information during target directed aiming tasks

3 has revealed the effect is enhanced through increased practice (see Lawrence et al., 2012;

4 Proteau \& Cournoyer, 1990). However, our analyses between early and late transfer

5 specificity effects on RT data revealed no significant differences. This finding indicates that

6 the typical increase in the specificity effect as a function of exposure (Lawrence et al., 2012;

7 Proteau \& Cournoyer, 1990) was not observed in the current anxiety-performance specificity

8 data. Nevertheless, whilst we did not observe a significant increase in the specificity effect

9 following increased exposure to a particular anxiety state, the change in offline processes

10 (RT) as a result of the anxiety-performance specificity effect never actually significantly

11 decreased as a function of exposure offering further support for the anxiety-performance

12 specificity effect at the systems offline processing level.

The results of the MT dependent measure, revealed different specificity effects for the two experimental groups and for the two transfer phases (early and late) of the experiment. Specifically, only the anxiety-control group demonstrated a significant increase in MT when conditions of anxiety were changed and this anxiety-performance specificity effect was only

17 present at late transfer. Whilst we hypothesised that any observed increases in RT would be accompanied by a reduction in MTs, our significant increase in MT for the anxiety-control group and non-significant change in MT between acquisition and late transfer for the controlanxiety group can be explained via our hypothesised proposal of an optimisation movement

21 control strategy. That is, similar to our original hypotheses, changes in the pre-planning

22 offline processes of movement control (RT) were a deliberate strategy adopted by

23 participants to combat both the change in anxiety and the empirically evidenced difficulty in 
This research was accepted in its current form for publication in Anxiety, Stress, and Coping on 21.09.2017

1 utilising online processes when anxiety was present (Lawrence et al., 2012). The increase in

2 MT in the anxiety-control group could also be the result of a deliberate strategy. One that was

3 designed to help combat the anxiety-performance specificity effect by deliberately slowing

4 movement trajectories under the control transfer phase in order to use the now available

5 online processes; something that was not afforded during the previous anxiety mood state

6 (see Lawrence et al., 2012). In the situation where anxiety was added (control-anxiety group)

7 no significant increase or decrease in MT was observed because online processes were

8 deemed less effective (compared to the low anxiety control condition). Thus, participants

9 utilised the extra time for offline control processes (RT), which resulted from the anxiety-

10 performance specificity effect, to ensure movements were planned without the need for such

11 online control processes.

12 It is important to note that the RT and MT performance measures of the current

13 investigation could be more refined in order to explore the micro details of the planning and

14 online control of movement execution in greater detail. It is recommended that future

15 research measure the variability of movements trajectories or parse trajectories into initial

16 planning impulses and discrete online movement adjustments (for a review, see Khan et al.,

$172006^{a}$ ) in order to explore our proposed anxiety-specificity centred movement planning and

18 online control optimisation strategy in more detail. A further limitation could be associated

19 with the inclusion of the need to increase performance (reduce RT and producer faster MTs)

20 in order to meet the monetary aspects of the pressure transfer test. Whilst the pressure

21 manipulation included a wealth of intrinsic and extrinsic competition and ego deceptive

22 threats (i.e., a public leader and loser board, real-time external viewing of performance and

23 associated note taking, the loss of money for a randomly partnered participant) the 
This research was accepted in its current form for publication in Anxiety, Stress, and Coping on 21.09.2017

1 requirement to specifically increase performance speed is not ideal given that the effects of

2 pressure were quantified via associated changes in RT and MT measures. Of course, since

3 the current experiment included both specific and non-specific performance associated

4 pressure manipulations, one cannot confidently hold either to the cause and effect

5 relationship observed between pressure and the online and offline changes to performance.

6 Indeed, this limitation is probably true of most of the pressure (stress)-performance literature

7 whereby aspects of pressure manipulations are specific to increases in performance and the

8 effects of pressure then quantified via those specific measures. As such, it is recommended

9 that future research use manipulations that focus of intrinsic and extrinsic competition and

10 ego deceptive threats that do not rely on explicit performance instructions. For examples, see

11 those in parentheses above.

\section{Conclusion}

The purpose of the present experiment was to specifically examine what aspects of

14 motor control (i.e., online or offline) develop specificity. To achieve this specific aim, the

15 task allowed movement patterns to be separated into different performance variables. The

16 study associated RT with offline control processes, whereas movements times were

17 associated with online control processes. When considering the RT data, it is proposed that

18 the anxiety-control and control-anxiety groups developed a movement strategy to optimise

19 the sensory information present during acquisition and that this plan was specific to the

20 anxiety state that was present during that phase of the experiment. Consequently, when the

21 anxiety state differed between acquisition and transfer, the movement plan developed was no

22 longer adequate to maintain performance without subsequent alterations in the strategies of

23 how offline and online control processes of movement execution were distributed. It appears 
This research was accepted in its current form for publication in Anxiety, Stress, and Coping on 21.09.2017

1 that under anxious conditions participants adopted to utilise offline processes (associated with

2 effective pre-planning) because the ability to plan movement parameters, implement pre-

3 planning movements, and/or utilise afferent information online to adjust movement

4 trajectories was reduced (also see Lawrence et al., 2012). This reliance on offline aspects for

5 motor control may be associated with a non-automatic, effortful, and conscious strategy i.e., a

6 strategy of planning movement parameters to reach the directed goal without subsequent

7 intervention. With this strategy being employed to optimise movement control by attempting

8 to combat the possible disruption to the proposed more automatic and reflexive processes

9 (Biere \& Proteau, 2011) involved with the online processes associated with the adjustment of

10 movement online.

11 References

12 Adam, J. J., Nieuwenstein, J. H., Huys, R., Paas, F. G., Kingma, H., Willems, P., \& Werry, 13 M. (2000). Control of rapid aimed hand movements: the one-target advantage. Journal of Experimental Psychology: Human Perception and Performance, 26, 295 312. doi:10.1037//0096-1523.26.1.295

Baumeister, R. F., \& Showers, C. J. (1986). A review of paradoxical performance effects: Choking under pressure in sports and mental tests. Journal of Social Psychology,16, 361-383. doi: 10.1002/ejsp.2420160405

Beilock, S. L., \& Gray, R. (2007). Why do athletes “choke” under pressure? In G. Tenenbaum\& R. C. Ecklund (Eds.), Handbook of sport psychology, ( $\left.{ }^{\text {rd }} \mathrm{Ed}\right), 425-$ 444. Hoboken, NH: Wiley. doi: 10.1002/9781118270011.ch19

Beilock, S. L., Jellison, W. A., Rydell, R. J., McConnell, A. R., \& Carr, T. H. (2006). On the causal mechanisms of stereotype threat: Can skills that don't rely heavily on working memory still be threatened? Personality and Social Psychology Bulletin, 32, 10591071. doi: 10.1177/0146167206288489 
This research was accepted in its current form for publication in Anxiety, Stress, and Coping on 21.09.2017

1 Bower, G. H., Monteiro, K. P., \& Gilligan, S. G. (1978). Emotional mood as a context for learning and recall. Journal of Verbal Learning and Verbal Behavior, 17, 573-585. doi: 0022-5371/78/0 175-0573502.00/0

Brière, J., \& Proteau, L. (2011). Automatic movement error detection and correction processes in reaching movements. Experimental Brain Research, 208, 39-50. doi: $10.1007 / \mathrm{s} 00221-010-2458-1$

Chamberlin, C. J., \& Magill, R. A. (1989). Preparation and control of rapid, multisegmented responses in simple and choice environments. Research Quarterly for Exercise and Sport, 60, 256-267. doi: 10.1080/02701367.1989.10607449

Coombes, S. A., Higgins, T., Gamble, K. M., Cauraugh, J. H., \& Janelle, C. M. (2009). Attentional control theory: Anxiety, emotions, and motor planning. Journal of Anxiety Disorders, 23, 1072-1079. doi: 10.1016/j.janxdis.2009.07.009

Eysenck, M. W., Derakshan, N., Santos, R., \& Calvo, M. G. (2007) Anxiety and cognitive performance: Attentional control theory. Emotion 7, 236-353. doi: 10.1037/15283542.7.2.336

Fischman, M. G. \& Reeve, T. G. . (1992). Slower movement times may not necessarily imply on-line programming. Journal of Human Movement Studies, 2, 131-144.

Gilligan, S. G., \& Bower, G. H. (1983). Reminding and mood-congruent memory. Bulletin of the Psychonomic Society, 21, 431-434. doi: 10.3758/BF03330000

Henry, F. M., \& Rogers, D. E. (1960). Increased response latency for complicated movements and a "memory drum" theory of neuromotor reaction. Research Quarterly, 31, 448-458. doi: 10.1080/10671188.1960.10762052

Khan, M. A., \& Franks, I. M. (2000). The effect of practice on component submovements is dependent on the availability of visual feedback. Journal of motor behaviour, 32, 227 240. doi: 10.1080/00222890009601374

Khan, M., Franks, I., Elliott, D., Lawrence, G., Chua, R., Bernier, P., Hansen, S., \& Weeks, D. (2006) $)^{\mathrm{a}}$. Inferring online and offline processing of visual feedback in targetdirected movements from kinematic data. Neuroscience and Biobehavioral Reviews, 30, 1106-1121. doi: 10.1016/j.neubiorev.2003.05.002

Khan, M. A., Lawrence, G. P., Buckolz, E., \& Franks, I. M. (2006) $)^{\text {b }}$ Programming strategies for rapid aiming movements under simple and choice reaction time conditions. The 
This research was accepted in its current form for publication in Anxiety, Stress, and Coping on 21.09.2017

Quarterly Journal of Experimental Psychology, 59, 524-542. doi: $10.1080 / 02724980443000809$

Khan, M. A., Lawrence, G. P., Franks, I. M., \& Buckloz, E. (2004). The utilization of visual feedback from peripheral and central vision in the control of direction. Experimental Brain Research, 158, 241-251. doi: 10.1007/s00221-004-1897-y

Krane, V. (1994). The Mental Readiness Form as a Measure of Competitive State Anxiety. The Sport Psychologist, 8, 189-202. doi: 10.1123/tsp.8.2.189

Lawrence, G. P., Cassell, V, E., Beattie, S., Woodman, T., Khan, M. A., Hardy, L., \& Gottwald, V. M. (2014). Practice with anxiety improves performance, but only when anxious: Evidence for the specificity of practice hypothesis. Psychological Research, 78, 634-650. doi: 10.1007s00426-013-0521-9

Lawrence, G. P., Khan, M. A., Buckolz, E., \& Oldham, T. (2006). The contribution of peripheral and central vision in the control of movement amplitude. Human Movement Science, 25, 326-338. doi: 10.1016/j.humov.2006.02.001

Lawrence, G. P., Khan, M. A., \& Hardy, L. (2012). The effects of state anxiety on the online and offline control of fast target directed movements. Psychological Research, 77, 422-433. doi: 10.1007/s00426-012-0440-1

Lawrence, G. P., Khan, M. A., Mourton, S., \& Bernier, P. (2011). The reliance on visual feedback for online and offline processing. Motor Control, 15, 232-246. doi: 10.1123/mcj.15.2.232

Mackrous, I., \& Proteau, L. (2007). Specificity of practice results from differences in movement planning strategies. Experimental Brain Research, 183, 181-193. doi: $10.1007 / \mathrm{s} 00221-007-1031-\mathrm{z}$

Masters, R. S. W. (1992). Knowledge, nerves and know-how - the role of explicit versus implicit knowledge in the breakdown of a complex motor skill under pressure. British Journal of Psychology, 83, 343-358. doi: 10.1111/j.2044-8295.1992.tb02446.x

Nieuwenhuys, A., \& Oudejans, R. R. D. (2010). Effects of anxiety on handgun shooting behaviour of police officers: a pilot study. Anxiety, Stress and Coping, 23, 225-233. doi: 10.1080/10615800902977494 
This research was accepted in its current form for publication in Anxiety, Stress, and Coping on 21.09.2017

1 Oudejans, R. R. D., \& Pijpers, J. R. R. (2009). Training with anxiety has a positive effect on expert perceptual-motor performance under pressure. Quarterly Journal of Experimental Psychology, 62, 1631-1647. doi: 10.1080/17470210802557702

Proteau, L. (1992). On the specificity of learning and the role of visual information for movement control. In L. Proteau \& D. Elliott (Eds.), Vision and motor control (pp. 67-103). Amsterdam: North-Holland. doi: 10.1016/s0166-4115(08)620117

Proteau, L., \& Cournoyer, J. (1990). Vision of the stylus in a manual aiming task: the effects of practice. Quarterly Journal of Experimental Psychology Section a-Human Experimental Psychology, 42, 811-828. doi: 10.1080/14640749008401251

Proteau, L., \& Marteniuk, R. G. (1993). Static visual information and the learning and control of a manual aiming movement. Human Movement Science, 12, 515-536. doi: 10.1016/0167-9457(93)90003-8

Proteau, L., Marteniuk, R. G., Girouard, Y., \& Dugas, C. (1987). On the type of information used to control and learn an aiming movement after moderate and extensive training. Human Movement Science, 6, 181-199. doi: 10.1016/0167-9457(87)90011-x

Schare, M. L., Lisman, S. A., \& Spear, N. E. (1984). The effects of mood variation on statedependent retention. Cognitive Therapy and Research, 8, 387-407. doi: 014759t6/84/0800-0387503.50/0

Schmidt, R. A., Zelaznik, H., Hawkins, B., Frank, J. S., \& Quinn, J. T. (1979). Motor-Output Variability - Theory for the Accuracy of Rapid Motor Acts. Psychological Review, 86, 415-451. doi: 0033-29SX/79/860S-041S\$00.7S

Zijlstra, F. (1993). Efficiency in work behaviour: A design approach for modern tools, Delft, Delft University. doi: d97a028b-c3dc-4930-b2ab-a7877993a17f 
This research was accepted in its current form for publication in Anxiety, Stress, and Coping on 21.09.2017

\section{Figure Captions}

7 Figure 1. Schematic of the target layout and the movement patterns for the three separate 8 stimulus-response pairings.

9 Figure 2. Anxiety (MRF-3 worry scale), Effort (RSME), RT (msec), and Overall Movement

10 Time (msec) data as a function group and experimental phase. Panel A represents data at 11 early transfer. Panel B represents data at late transfer. * depicts the breakdown of the 12 interaction and represents a significant $(p<.05)$ within group change from the previous 13 experimental phase. 
This research was accepted in its current form for publication in Anxiety, Stress, and Coping on 21.09.2017 